Article

\title{
Synergistic Study of Solid Lubricant Nano-Additives Incorporated in canola oil for Enhancing Energy Efficiency and Sustainability
}

\author{
Soumya Sikdar, Md Hafizur Rahman (D) and Pradeep L. Menezes *(D)
}

check for

updates

Citation: Sikdar, S.; Rahman, M.H.; Menezes, P.L. Synergistic Study of Solid Lubricant Nano-Additives Incorporated in canola oil for Enhancing Energy Efficiency and Sustainability. Sustainability 2022, 14 , 290. https://doi.org/10.3390/ su14010290

Academic Editors: P. Senthil Kumar, Dai-Viet N. Vo, N. Selvaraju and S. Ramalingam

Received: 18 November 2021 Accepted: 24 December 2021 Published: 28 December 2021

Publisher's Note: MDPI stays neutral with regard to jurisdictional claims in published maps and institutional affiliations.

Copyright: (c) 2021 by the authors Licensee MDPI, Basel, Switzerland. This article is an open access article distributed under the terms and conditions of the Creative Commons Attribution (CC BY) license (https:// creativecommons.org/licenses/by/ $4.0 /)$.

\author{
Department of Mechanical Engineering, University of Nevada, Reno, NV 89557, USA; \\ soumyasikdar@nevada.unr.edu (S.S.); mhrsazal@nevada.unr.edu (M.H.R.) \\ * Correspondence: pmenezes@unr.edu
}

\begin{abstract}
In recent years, with the development of eco-friendly lubricants, different vegetable oils have been studied and found to improve the overall tribological performance compared to petroleumbased oils. Being one of the commonly used vegetable oils, canola oil has become popular due to its non-toxicity and low cost. However, this bio-lubricant lacks tribological performance compared to petroleum-based oils. To improve its performance, sustainable solid additives such as graphene nanoplatelet (GNP) and hexagonal boron nitride ( $\mathrm{hBN}$ ) have recently gained the researcher's attention. While incorporating nanomaterials in the oil as additives is a promising way to improve base oil's performance, the excessive use of nanoparticles can introduce undesirable effects. This study investigated canola oil's tribological performances with the addition of $0.5,1.0,1.5$, and $2.0 \mathrm{wt}$.\% GNP and $0.5,1.0$, and $1.5 \mathrm{wt} . \% \mathrm{hBN}$ nanoparticles. The dynamic viscosities of these seven settings showed higher viscosity for GNP-incorporated oils compared to that with hBN. The boundary lubrication regime was targeted for the coefficient of friction (COF) and wear analyses during each pin on the disk test. It was observed that for the GNP, $1.5 \mathrm{wt}$. $\%$ provided the minimum COF ( $52 \%$ less than base oil), whereas, for the hBN, $1.0 \mathrm{wt}$. \% provided the lowest ( $40 \%$ less than base oil) values. Based on these insights, three nano lubricant mixtures were formulated by incorporating both GNP and hBN settings in different ratios. These mixtures provided an optimum positive synergy by reducing $56 \%$ friction and $90 \%$ wear compared to the base oil. These percentage values were significantly more compared to both GNP and hBN based lubricants in their individual settings. These improvements in the mixture were due to a composite film formed which protected the interacting surfaces and also due to the polishing mechanisms. Therefore, incorporating both these nanoparticles in canola oil could reduce friction and wear and thus help in better energy conservation.
\end{abstract}

Keywords: solid lubricant; bio-based oil; eco-friendly; sustainable materials; conservation; pollution; toxicity

\section{Introduction}

Bio-based oils obtained from vegetables have been used as lubricants for minimizing friction and wear from ancient times [1,2]. However, from the beginning of the 20th century, researches on the properties of natural oils have gained wider attention [3,4]. Recently, in an attempt to minimize the use of petroleum-based lubricants owing to concerns of environmental protection, increase in price, and depletion of crude oil reserves, there has been an increase in research pertaining to natural oils [5,6]. Studies have shown that compared to synthetic oils, bio-based oils from vegetables possess lower volatility, higher lubricity, higher load-carrying potential, higher viscosity index, and higher shear stability $[1,7]$. Hence they can be a suitable alternative to petroleum-based oils. One of the main reasons nowadays for inclination towards bio-based oils is due to their constitution of triacylglycerol and long chains of polar fatty acids [8]. These constitutions of bio-based oils 
are advantageous for boundary lubrication regime due to their close-packed nature, ability to stick to metallic surfaces, and development of a monolayer that is good for reducing friction and wear [9]. Many studies related to bio-lubricants formulated from vegetable oils like canola oil have tried to understand the impact of the oil's different fatty acids, their usage as pure lubricants, or as additives mixed with synthetic oils $[1,10,11]$. When compared with petroleum-based oils, it has been observed from studies that vegetable-based oils possess better dispersancy, higher flash point, lesser loss of friction, enhanced efficiency, and higher power output $[12,13]$. However, in spite of these benefits from the vegetablebased oils, they have a number of limitations, such as bacterial deterioration, solidification at low temperatures, and inferior thermal-oxidation stability to name a few [14]. However, recently there has been a renewed interest in vegetable-based oils over petroleum-based lubricants because of the latter's toxic nature, higher costs, and environmental pollution. The spillage, leakage of used petroleum-based oils can cause them to return back to the surface of the earth. In addition, these oils are not significantly biodegradable. Thus, it becomes a challenge to dispose of the waste oils. Bartz [15] studied various oils and found that for petroleum-based oils, the limiting value of biodegradability is around 30 to $65 \%$, whereas, for bio-based oils, it is around $95 \%$. To mitigate these degradability problems, researchers are working extensively to find a scope in renewable and more environmentally friendly sustainable bio-friendly lubricants.

The performance and efficiency of lubricants can be improved by incorporating small weight percentages of nano and micro-sized particle additives [16,17]. The incorporation of nanoparticles into vegetable oils has now created a lot of interest amongst researchers and experimental studies have exhibited their multiple beneficial effects $[11,18]$. One of these effects is providing a lower coefficient of friction and lower wear $[19,20]$. One of the important attributes for superior lubrication properties of solid nanoparticles is their potential to shear between the interacting surfaces as well as due to their inherent layered structures [21]. The incorporation of inorganic solid nanoparticles such as nano clays has been exploited for the fabrication of Pickering emulsions. These emulsions can be potentially used as green alternatives for several applications such as food packaging, decontamination, and restoration to name a few [22-24].

Suresha et al. [25] incorporated graphene nanoplatelets (GNP) in neem oil with various concentrations. It was observed that $1.0 \mathrm{wt} . \% \mathrm{GNP}$ could reduce the coefficient of friction by $41 \%$ and also the wear scar diameter significantly. Reeves et al. [16] investigated the influence of incorporation of different sized hexagonal boron nitride (hBN) particles into various vegetable oils. It was observed that the friction reduced from 8 to $64 \%$ when particle sizes were changed from micron size to nano size. Similarly, there was a decrease in wear volume from 13 to $70 \%$ when the particle size changed from micron to nano size. In addition to the nanoparticle size, there are various other factors that influence the nature of nanoparticles incorporated in a lubricant, such as geometry, chemical, and physical properties to name a few [26]. Table 1 provides a brief summary of tribological equipment that different researchers have used for studying the tribological performance of a few vegetable oil-based nano lubricants. 
Table 1. Details of tribological experiments performed with a few vegetable oil-based nano lubricants.

\begin{tabular}{|c|c|c|c|c|c|}
\hline Lubricant Sample & Additives & $\begin{array}{l}\text { Tribological } \\
\text { Equipment Set-Up }\end{array}$ & $\begin{array}{l}\text { Observation } \\
\text { from Results }\end{array}$ & Mechanism & References \\
\hline Canola Oil & Graphene & Pin on disk & $\begin{array}{l}\text { Coefficient of friction } \\
\text { improved by } 11 \text { to } \\
26 \% \text {. Wear rate } \\
\text { improved by } 47 \text { to } 83 \%\end{array}$ & $\begin{array}{l}\text { Protective film } \\
\text { formation }\end{array}$ & [10] \\
\hline Avocado Oil & $\begin{array}{l}\text { Hexagonal } \\
\text { boron nitride }\end{array}$ & Pin on disk & $\begin{array}{l}\text { Coefficient of friction } \\
\text { improved by } 8 \text { to } 64 \% \text {. } \\
\text { Wear volume } \\
\text { improved by } 13 \text { to } 72 \%\end{array}$ & $\begin{array}{l}\text { Protective transfer } \\
\text { film formation }\end{array}$ & [16] \\
\hline $\begin{array}{l}\text { Modified } \\
\text { Jatropha Oil }\end{array}$ & $\begin{array}{l}\text { Hexagonal } \\
\text { boron nitride }\end{array}$ & $\begin{array}{l}\text { Four ball tester } \\
\text { with ASTM } \\
\text { D4172 standards }\end{array}$ & $\begin{array}{l}\text { Coefficient of friction } \\
\text { improved by } 20 \text { to } 57 \% \text {. } \\
\text { However, wear scar } \\
\text { diameter increased }\end{array}$ & $\begin{array}{l}\text { Rolling effect } \\
\text { and protective } \\
\text { film formation }\end{array}$ & [27] \\
\hline Mahua Oil & Graphene & $\begin{array}{l}\text { Four ball tester } \\
\text { with ASTM } \\
\text { D4172 standards }\end{array}$ & $\begin{array}{l}\text { Coefficient of friction } \\
\text { improved by } 17.07 \% \\
\text { and wear scar } \\
\text { diameter by } 15.15 \%\end{array}$ & $\begin{array}{l}\text { Protective film } \\
\text { formation }\end{array}$ & [28] \\
\hline $\begin{array}{l}\text { Cashew } \\
\text { nutshell liquid }\end{array}$ & $\begin{array}{l}\text { Reduced } \\
\text { graphene oxide }\end{array}$ & $\begin{array}{l}\text { Four ball tester } \\
\text { with ASTM } \\
\text { D4172 standards }\end{array}$ & $\begin{array}{l}\text { Significant } \\
\text { improvement in } \\
\text { reduction of coefficient } \\
\text { of friction and wear } \\
\text { scar diameter }\end{array}$ & $\begin{array}{l}\text { Protective film } \\
\text { formation }\end{array}$ & [29] \\
\hline Castor oil & Graphene & $\begin{array}{l}\text { Four ball tester } \\
\text { with ASTM } \\
\text { D4172 standards }\end{array}$ & $\begin{array}{l}\text { Significant } \\
\text { improvement in } \\
\text { reduction of coefficient } \\
\text { of friction and wear } \\
\text { scar diameter }\end{array}$ & $\begin{array}{l}\text { Protective film } \\
\text { formation }\end{array}$ & {$[30]$} \\
\hline $\begin{array}{l}\text { Soyabean oil (SBO), } \\
\text { Palm oil (PO) }\end{array}$ & $\begin{array}{l}\text { Hexagonal } \\
\text { Boron Nitride }\end{array}$ & Ball on flat set-up & $\begin{array}{l}\text { Coefficient of friction } \\
\text { increased for both SBO } \\
\text { and PO but a loss of } \\
\text { mass reduced by } 12 \\
\text { and } 5 \%\end{array}$ & $\begin{array}{l}\text { Protective film } \\
\text { formation }\end{array}$ & [31] \\
\hline
\end{tabular}

Graphene formed by $\mathrm{sp}^{2}$ bond is one of the most prominent nanomaterials used extensively as an additive for lubricant applications. Graphene possesses good mechanical strength, good thermal conductivity, potential to minimize damage caused by wear, and impermeability to liquids and gases [32,33]. These properties provide graphene with a unique advantage to be used as a lubricant additive. In addition, GNP is made up of only $\mathrm{C}$ and does not contain any toxic elements like P or S. Hence, they could be considered to be environmentally friendly.

Hexagonal boron nitride (hBN) is a renowned lamella-shaped solid lubricant. They are well known for their low interlayer friction and potential to create a protective boundary layer [16,34]. It is white in color and is sometimes referred to as white graphite. In hBN, boron and nitrogen atoms are bonded together by strong covalent bonds in each layer. On the other hand, weak Van der Waals forces hold the bonding between the layers for $\mathrm{hBN}$. The hBN powders are efficient for a wide range of applications to minimize friction and wear [35]. Additionally, $\mathrm{hBN}$ is environmentally friendly and not reactive to a majority of chemicals [11]. Hence, it is considered an interesting additive for enhancing the performance of lubricating oils.

In recent years, there has been a significant increase in research on bio-based lubricants. Amongst the various bio-lubricants available in the market, canola oil is one of the cheapest and also is readily available. Canola oil possesses a variety of monosaturated and polysaturated fatty acids. Additionally, it has surface tension and viscosity properties 
similar to a few petroleum-based lubricants, employed in metal forming and stamping applications [16]. There have been tribological studies performed on canola oil with graphene and $\mathrm{hBN}$ additives separately $[10,16]$. However, no tribological studies were reported using canola oil-based hybrid (combination of hBN and GNPs) nano lubricants. These studies have shown that additives incorporated in the canola oil exhibit enhanced tribological performance compared to pure oil $[11,36]$. In this study, the authors seek to examine the influence of two different solid additives, namely GNP and hBN, incorporated into the canola oil separately. Later, a potential synergistic behavior is also examined by mixing the GNP and $\mathrm{hBN}$ in specific proportions.

\section{Experimental Details}

\subsection{Materials and Methods}

In this study, pure canola oil and its formulated nano lubricants were investigated. Here, GNP and hBN solid lubricant additives were incorporated in the canola oil to form nano lubricants (Figure 1). These nano lubricants were investigated with a Rtec tribometer using a ball-on-disk setup. The canola oil was purchased (manufactured by Great Value) from Walmart, Bentonville, AR, USA. The relative density of the canola oil was noted from the literature study [37]. For the tribological experiments, a $50 \mathrm{~mm}$ diameter cylindricalshaped Al 6061 alloy was considered as the disk material. In addition, a $6.35 \mathrm{~mm}$ diameter sphere-shaped 52,100 alloy was considered as the ball sample. The disk and ball materials were purchased from McMaster Carr, Elmhurst, IL, USA. The chemical composition of the ball and the disk materials are mentioned in Table 2.

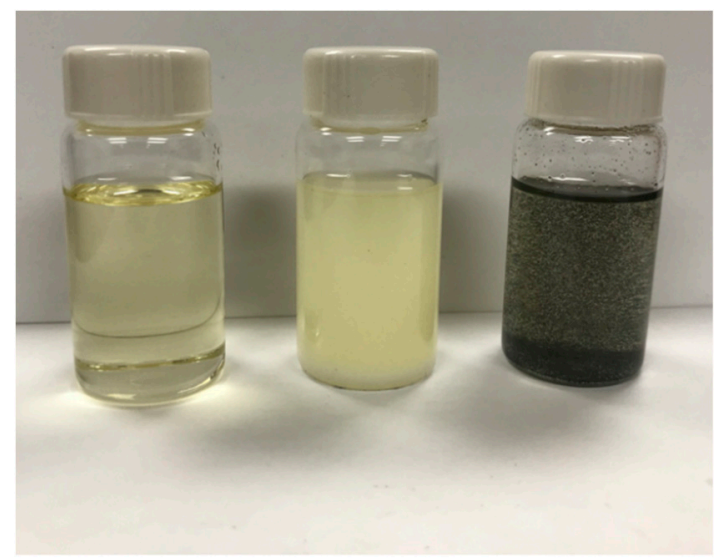

(a)

(b)

(c)

Figure 1. Image of lubricant samples for (a) pure canola oil, (b) canola oil incorporated with hBN, and (c) canola oil incorporated with GNP.

Table 2. Chemical composition (\%) of disk and ball material.

\begin{tabular}{lllllllllll}
\hline Alloy & Fe & Cr & C & Mn & Si & S & P & Al & Mg & Cu \\
\hline Al 6061 & - & 0.20 & - & - & 0.6 & - & - & 97.9 & 1.0 & 0.28 \\
52,100 & $96.5-97.32$ & $1.3-1.6$ & $0.98-1.1$ & $0.25-0.45$ & $0.15-0.3$ & 0.025 & 0.025 & - & - & - \\
\hline
\end{tabular}

The Vickers hardness value of $\mathrm{Al} 6061$ was $107 \mathrm{HV}$, and of 52, 100 alloy it was $848 \mathrm{HV}$. During the tribological tests, the ball and the disk were fully immersed by the lubricant in order to ensure that the tribo-pair was constantly lubricated during the entire experiment. The ball-on-disk tests was performed at room temperature (around $25^{\circ} \mathrm{C}$ ) and lab humidity conditions (around 50\% relative humidity). Each of the tests was performed three times under the same testing conditions to exhibit the repeatability of the experimental data.

The $\mathrm{Al} 6061$ disks were polished with random surface textures. The disks were initially polished with 120, 240, 400, 600, and 1000 papers (Buehler, Lake Bluff, IL, USA) and later 
cloth polished using diamond paste ( 1 and 0.05 micron). The disks were polished to have an average surface roughness value, $R_{a}=0.1 \pm 0.05 \mu \mathrm{m}$

\subsection{Preparation of Nano Lubricants}

For this study, the GNP and hBN additives were procured from Acros Organics, Carlsbad, CA, USA, and Lower Friction, Mississauga, ON, Canada. Table 3 summarizes the properties of the nano additives employed in this study based on the manufacturer's catalog.

Table 3. Properties of the nano additives.

\begin{tabular}{lllllll}
\hline Additive & Thickness $(\mathbf{n m})$ & Purity $\mathbf{( \% )}$ & Density $\left(\mathbf{g} / \mathbf{c m}^{3}\right)$ & Shape & Color \\
\hline hBN & 70 & 99.85 & 2.30 & hexagonal & white \\
\hline GNP & $2-10$ & 99.90 & 2.25 & layered & grey \\
\hline
\end{tabular}

During the nano lubricants' preparation, the nano additives were first incorporated at various weight fractions into the canola oil inside a beaker. For the formulation of GNPbased nano lubricants, $10 \mathrm{~mL}$ of pure canola oil was used and separately mixed with 0.5 , $1.0,1.5$, and $2.0 \mathrm{wt} . \%$ of GNP. Similarly, for the formulation of hBN-based nano lubricants, $10 \mathrm{~mL}$ of pure canola oil was used and separately mixed with $0.5,1.0$, and $1.5 \mathrm{wt} . \%$ of hBN.

Next, the incorporated nano additives were mixed thoroughly utilizing a vortex mixer (VWR, Radnor, PA, USA) to form nano lubricant mixtures. The mixtures were initially shaken for around $20 \mathrm{~min}$ using the vortex mixer at room temperature and then put in an ultrasonicator for $2 \mathrm{~h}$ at $60^{\circ} \mathrm{C}$ [10]. The objective of this process was to ensure that the incorporated nano additives were uniformly dispersed in the oil. Initially, the GNP nano additives were incorporated at $0.5,1.0,1.5$, and $2.0 \%$ by weight in a measured amount to the canola oil in order to understand their concentration influence on friction and wear. Later, the $\mathrm{hBN}$ nano additives were also incorporated at $0.5,1.0$, and $1.5 \%$ by weight in a similar measured amount to the canola oil to study friction and wear performance. Amongst the different concentrations of GNP and hBN nano lubricants prepared, the ones that showed the lowest coefficient of friction and wear volume were considered as the optimum concentrations. These optimum concentrations were further experimented with to analyze the potential synergy of both GNP and hBN conjugate mixture incorporated in the canola oil. To formulate the conjugate mixtures, we took into consideration the optimum hBN (1.0 wt.\%) and optimum GNP (1.5 wt.\%) concentrations. These optimum mixtures of hBN and GNP-based nano lubricants were mixed in different proportions, such as $25 \%$ of $1.0 \mathrm{wt} . \% \mathrm{hBN}+75 \%$ of $1.5 \mathrm{wt} . \% \mathrm{GNP}, 50 \%$ of $1.0 \mathrm{wt} . \% \mathrm{hBN}+50 \%$ of $1.5 \mathrm{wt} . \% \mathrm{GNP}$, and $75 \%$ of $1.0 \mathrm{wt} . \% \mathrm{hBN}+25 \%$ of $1.5 \mathrm{wt} . \%$ GNP.

Once the nano lubricant samples were prepared, their dynamic viscosity was then observed at $40^{\circ} \mathrm{C}$ and $100{ }^{\circ} \mathrm{C}$. A Brookfield Ametek DV2T viscometer was employed to note down the dynamic viscosity of the nano lubricant samples. A pH meter was used to measure the $\mathrm{pH}$ value of the pure canola oil and its formulated nano lubricants. A Nicolet iS ${ }^{\mathrm{TM}}$ 50 spectrometer was employed to perform FTIR tests on the above-mentioned lubricants. The ball-on-disk tests were done immediately after the preparation of the canola oil-based nano lubricants to minimize particle agglomeration. Before performing the ball-on-disk tests, all the test specimens were cleaned with an acetone solution in the ultra sonicator and dried properly using an air blower. In addition, after completion of each ball-on-disk test, all the test specimens were thoroughly cleaned using hexane solution in the ultra sonicator followed by hot drying using the air blower. The ball-on-disk tests were performed with the specifications summarized in Table 4 . The parameters for the ball-on-disk tests were chosen such that they resulted in boundary lubrication regime conditions.

After completing the ball-on-disk tests, the wear track profiles of the disks were captured and analyzed using a 3D optical profilometer. The wear track formed on the disk post tribological tests was determined by a non-contact Nikon 3D Optical Profilometer with 
10X magnification and scan area of $1.19 \times 0.89 \mathrm{~mm}^{2}$. The profiles were useful to calculate the wear volume of the disks.

Table 4. Ball-on-disk test specifications.

\begin{tabular}{ll}
\hline Test Specifications & Numerical Value \\
\hline Sliding distance & $100 \mathrm{~m}$ \\
\hline Angular velocity & $21.5 \mathrm{rpm}$ \\
\hline Normal Load & $30 \mathrm{~N}$ \\
\hline Test duration & $2700 \mathrm{~s}$ \\
\hline Maximum hertzian contact pressure & $0.314 \mathrm{GPa}$ \\
\hline
\end{tabular}

\section{Results and Discussion}

\subsection{Viscosity and $p H$ of the Lubricants}

Viscosity is an important factor that is used to measure the resistance to flow and also internal friction of a fluid. Figure 2 depicts the influence of the GNP and hBN concentration on the dynamic viscosity of canola oil with respect to temperature. The incorporation of nano additives changes the color of the pure oil (Figure 1). It can be observed from Figure $2 \mathrm{a}$ that with a gradual increase in the concentration of the GNP nano additives, there was an enhancement of the dynamic viscosity. The reason for the high viscosity can be attributed to the fact that with the incorporation of small amounts of nano additives to the pure canola oil, the additives tend to attract each other due to Van der Waals forces. Consequently, the higher concentration of additives agglomerates because the layers between the oil cannot move freely, leading to an increase in the viscosity [38]. It was also noticed that with an increase in temperature, the dynamic viscosity of the nano lubricants decreases. Similarly, it can be observed from Figure $2 b$ that with an increase in the concentration of $\mathrm{hBN}$ nano additives, there was an increase in the dynamic viscosity. This enhancement of dynamic viscosity is observed at both $40{ }^{\circ} \mathrm{C}$ and $100{ }^{\circ} \mathrm{C}$. Further, it was observed that the increase in the viscosity was slightly more for the GNP-based nano lubricants compared to the hBN-based nano lubricants. Figure $2 \mathrm{c}$ represents the dynamic viscosity data of the canola oil-based hybrid lubricant mixtures. It can be observed from this figure that with an increase in the concentration of $\mathrm{hBN}$ in the hybrid lubricant mixture, there is also an increase in the dynamic viscosity at both mentioned temperatures.

However, the increase in viscosity with an increase in the concentration of additives is not very significant. This might be explained by the fact that the formulated nano lubricants behave like a Newtonian fluid, where the dynamic viscosity remains almost the same at a particular temperature. However, the reasoning for this nature of nano lubricants is still assumption-based [39].

The incorporation of nano additives was observed to increase the $\mathrm{pH}$ value of the canola oil-based nano lubricants (Figure 3). It was observed that for the pure canola oil and the formulated nano lubricants, the $\mathrm{pH}$ value was less than 7 , which refers to their slightly acidic nature. We also noticed that the incorporation of the nano additives to the canola oil reduced its acidity. In addition, it was observed that the hBN nano lubricant was more acidic in nature than the GNP nano lubricant. Amongst the hybrid lubricant mixtures, it was observed that the sample containing a higher concentration of hBN exhibited the lowest acidic nature.

\subsection{FTIR Analysis}

FTIR analysis was performed for the pure canola oil and its formulated nano lubricant samples. The FTIR data provided information on the presence of certain chemical bonds present in the canola oil. The data from the FTIR test were analyzed using the five-zone analysis method [40] and summarized in Table 5. The FTIR spectra of the pure canola oil and its formulated nano lubricants are shown in Figure 4. 
From Table 5, it was observed that the canola oil contains Alkyl sp3 C-H bond, Carboxylic acid (fatty acid), Ketone, and C-H bond stretching. Reeves et al. [41] reported that the presence of the fatty acid group, such as $\mathrm{COOH}$ was beneficial from a tribological study point of view. The peak observed at approximately $1750 \mathrm{~cm}^{-1}$ highlighted the presence of an ester group, which explains the presence of oxygenated compounds in the canola oil. For the canola oil formulated GNP and hBN nano lubricants, there was not much change in the structure of the peaks when analyzed. This probably indicated that the nano additives did not significantly chemically react with the canola oil. Instead, the nano additives remained as suspended particles that would have been beneficial for reducing friction and wear volume in our intended experimental study.

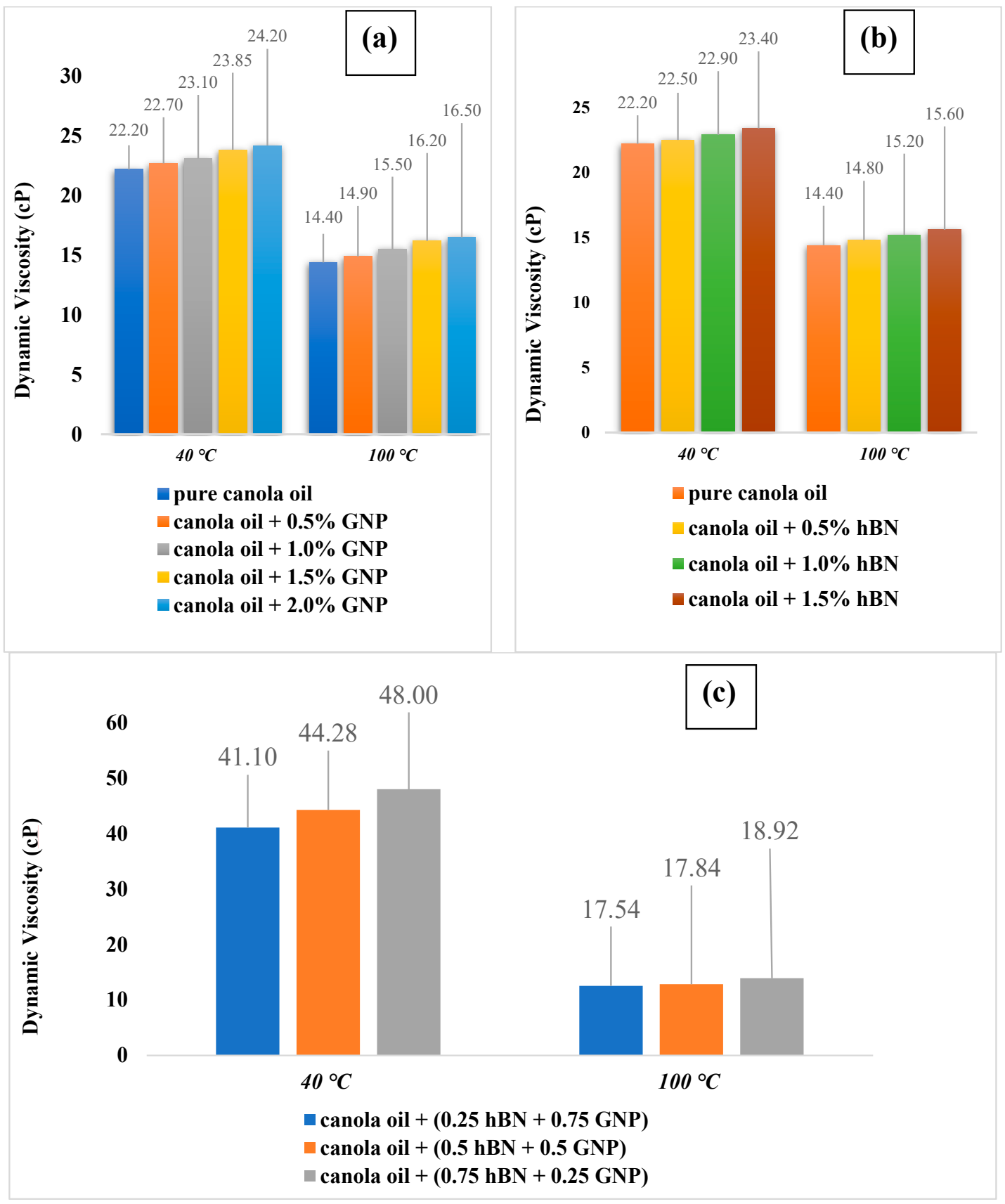

Figure 2. Dynamic viscosity of (a) canola oil incorporated with graphene nanoplatelet (GNP), (b) canola oil incorporated with hexagonal boron nitride $(\mathrm{hBN})$, and (c) canola oil incorporated with both hBN and GNP. 


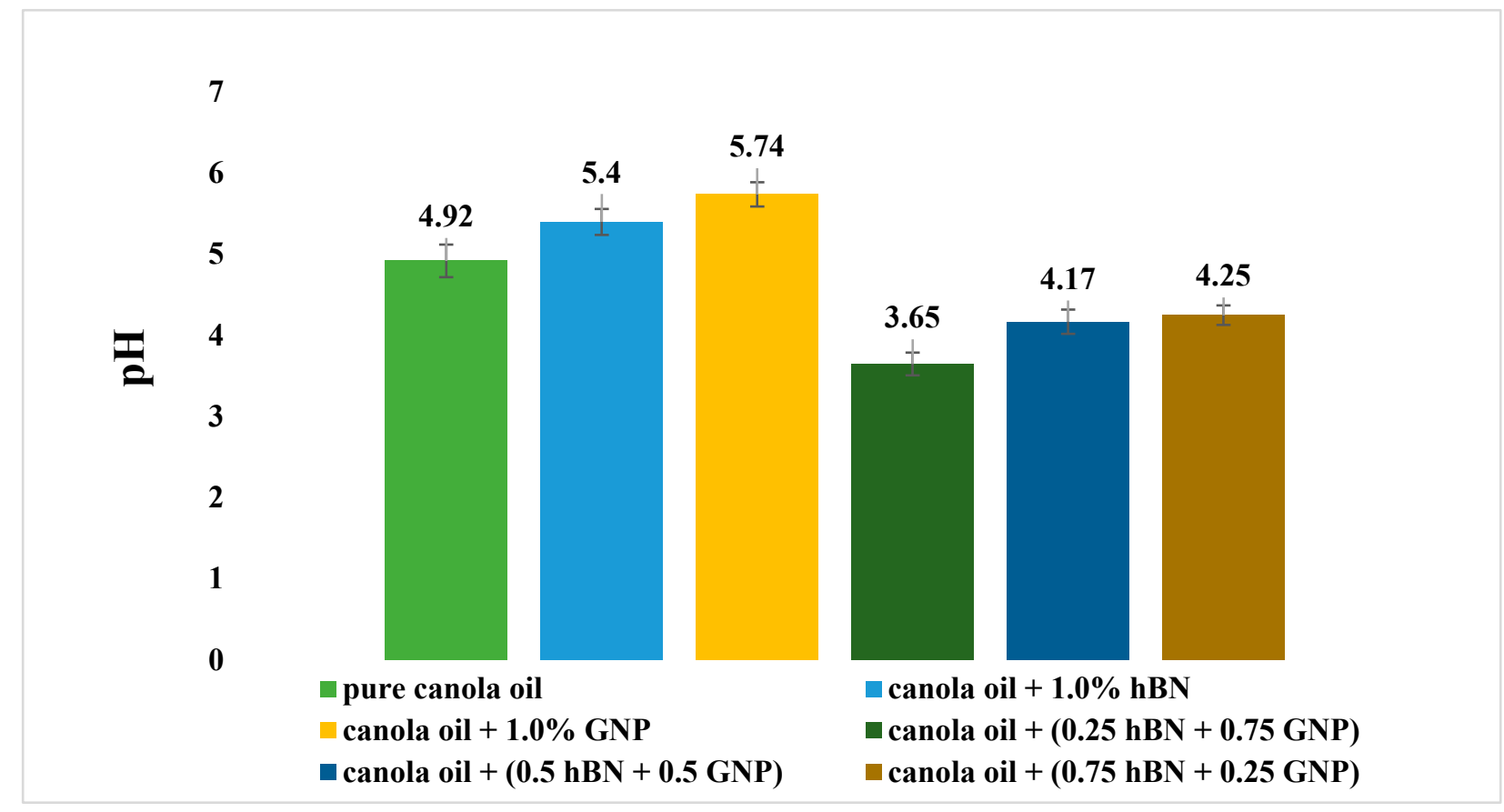

Figure 3. $\mathrm{pH}$ values of the pure canola oil and its formulated nano lubricants.

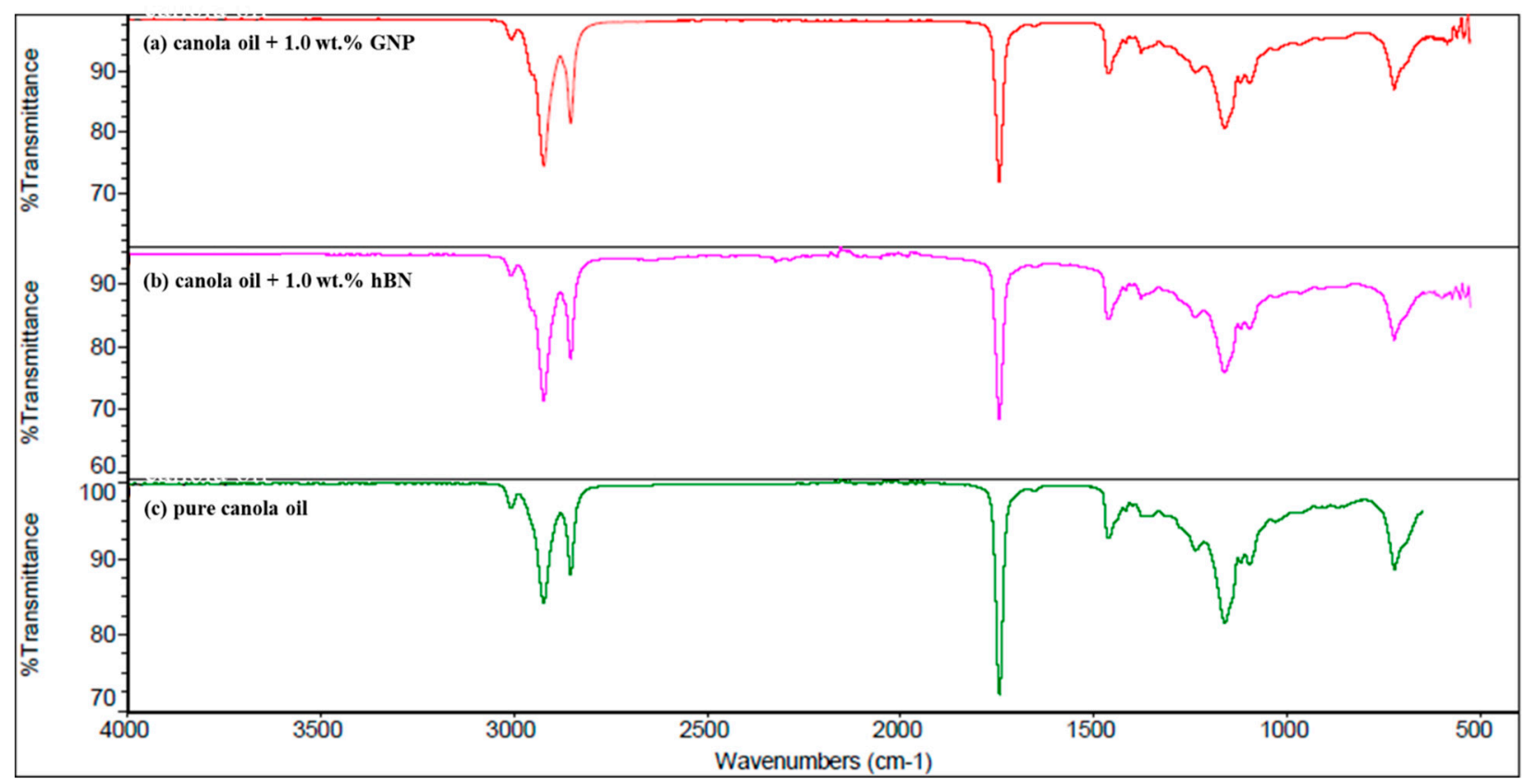

Figure 4. FTIR spectra of pure canola oil and its formulated nano lubricants.

\subsection{Friction Analysis}

The ball-on-disk tests were performed to provide an idea of the tribological performance of the formulated nano lubricants as shown in Figure 4. Canola oil contains almost $60 \%$ oleic acid. This acid helps in producing dense monolayers that get adsorbed onto mating surfaces thereby protecting the tribo-pair [16]. It was observed from Figure 5a that on the incorporation of GNP additives into the canola oil, there was a gradual decrease in the coefficient of friction (COF). This observation could be reasoned to the fact that the GNPs reduced the tribo-pair surface contact by occupying valleys of the asperities. Further, the GNPs tend to orient themselves parallel to the relative motion of the tribo-pair. The 
consequence of this was a decrease in the shear stress, which helped provide optimum lubrication. The incorporation of small quantities of GNP into the canola oil resulted in the reduction of contact area by forming a tribolayer on the worn surfaces. The incorporation of $0.5,1.0,1.5$, and $2.0 \mathrm{wt}$.\% of GNP helped in the reduction of COF by 17, 31, 52, and 15\% compared to pure canola oil. Here it was observed that the $1.5 \mathrm{wt}$.\% GNP provided the lowest $\mathrm{COF}$ and was considered to be the optimum concentration. The lowest reduction in the COF by the optimum GNP concentration can be attributed to the refinement in surface tension. Since the incorporation of nano additives to a base oil modifies its surface tension [42].

However, when the concentration of the GNP was increased beyond the optimum concentration, the nano lubricant increased the COF. This observation could be attributed to the fact of agglomeration of the GNPs due to their high surface activity as observed in other base lubricants from the literature [43]. The agglomeration could also be attributed to the high surface energy of the nano additives [44]. Hence it could be realized that an excessive concentration of the GNP could result in a negative performance in terms of the COF. It was also noted that a lower concentration of GNP compared to the optimum composition was also not beneficial in reducing the COF. This could be attributed to the fact that the lower concentration of GNP could not fully protect the tribo-pair surfaces.

Similarly, Figure 5b showed the comparison of the COF with an increase in the concentration of the hBN in the canola oil. The incorporation of $0.5,1.0$, and $1.5 \mathrm{wt} . \%$ of hBN into the canola oil helped in the reduction of the COF by 22,40 , and $17 \%$ compared to pure canola oil. The gradual incorporation of small quantities of the hBN additives helped in reducing the COF. This could be explained by the fact that the lamellar structure of hBN tends to fill the asperities by forming a protective layer. When the sliding operation takes place, the $\mathrm{hBN}$ orient their layers parallel to the direction of motion and slide over each other. This helped in the reduction of the COF. Here it was observed that the $1.0 \mathrm{wt} . \%$ provided the lowest COF and was considered to be the optimum concentration. It was observed that when the concentration of hBN was incremented beyond the optimum composition, there was an increase in the COF. This could be reasoned to the agglomeration of the hBN additives as observed in other lubricants from the literature [45]. Further, it was noted that the hBN nano lubricants with lower concentrations than the optimum composition were giving a higher COF. This might be because the low hBN in base oil could not fully protect the tribo-pair surfaces.

We observed that the $1.5 \mathrm{wt} . \%$ GNP and $1.0 \mathrm{wt} . \% \mathrm{hBN}$ were the optimum concentration for the ball-on-disk tests performed. Hence it would be interesting to observe the mixing of the $1.5 \mathrm{wt} . \% \mathrm{GNP}$ and $1.0 \mathrm{wt}$ \% hBN in various concentrations to study the tribological performance of the formulated hybrid nano lubricants.

The ball-on-disk tests were performed with the same test parameters using three combinations of GNP and hBN mixed in the canola oil as described in Section 2.2. The three hybrid nano lubricants mixtures were [canola oil $+(0.25 \mathrm{hBN}+0.75 \mathrm{GNP})$ ], [canola oil $+(0.5 \mathrm{hBN}+0.5 \mathrm{GNP})]$, and [canola oil $+(0.75 \mathrm{hBN}+0.25 \mathrm{GNP})]$ respectively. It could be observed from Figure 6 that the canola oil-based hybrid nano lubricant [canola oil + $(0.75 \mathrm{hBN}+0.25 \mathrm{GNP})]$ exhibited a lower friction behavior compared to others. It could be realized that this hybrid nano lubricant could provide a synergistic behavior. Similar synergistic behavior of this type of hybrid nano lubricant was also observed in other base oil from a literature study [46]. The three above-mentioned hybrid nano lubricants helped in reducing the COF by 42,51 , and $56 \%$ compared to the pure canola oil. It was noted that a higher concentration of $\mathrm{hBN}$ in the hybrid nano lubricant mixture was beneficial for reducing the COF. This fact could also be justified by Figure $2 \mathrm{c}$ where the nano lubricant mixture containing a higher concentration of $\mathrm{hBN}$ exhibited the highest dynamic viscosity. Higher viscosity of a lubricant provides an enhanced lubricating effect. It is anticipated that there will be a tribo-film formed at the interface of the tribo-pair by the hybrid nano lubricant. There are two potential ways in which the tribo-film can help in improving the hybrid nano lubricant's tribological performance. First, the nano additive mixtures are 
deposited and adsorbed on the tribo-pair. Second, the additives tribo-chemically react with the tribo-pair [47]. These bio-based hybrid lubricant mixtures may be used as an alternative lubricant for machining operations like milling and grinding as observed from the other literature case study [48].

Table 5. Observations from the FTIR spectroscopy for canola oil and its formulated nano lubricants.

\begin{tabular}{|c|c|c|c|c|c|c|}
\hline Chemical Compounds & $\begin{array}{l}\text { Frequency } \\
\text { Range }\left(\mathrm{cm}^{-1}\right)\end{array}$ & $\begin{array}{l}\text { Functional } \\
\text { Group }\end{array}$ & $\begin{array}{l}\text { Pure Canola } \\
\text { Oil }\end{array}$ & $\begin{array}{l}\text { Canola Oil + } \\
\text { GNP }\end{array}$ & $\begin{array}{l}\text { Canola Oil + } \\
\text { hBN }\end{array}$ & $\begin{array}{l}\text { Canola Oil + } \\
\text { hBN+ GNP }\end{array}$ \\
\hline Zone 1 & $3700-3200$ & & & & & \\
\hline Alcohol & $3650-3200$ & $-\mathrm{O}-\mathrm{H}$ & $\times$ & $\times$ & $\times$ & $\times$ \\
\hline Alkyne & $3340-3250$ & $\equiv \mathrm{C}-\mathrm{H}$ & $x$ & $x$ & $x$ & $x$ \\
\hline Zone 2 & $3200-2690$ & & & & & \\
\hline $\begin{array}{l}\text { Aryl or Vinyl sp2 } \\
\text { C-H bond }\end{array}$ & $3100-3000$ & $\equiv \mathrm{C}-\mathrm{H}$ & $\times$ & $\times$ & $\times$ & $\times$ \\
\hline Alkyl sp3 C-H bond & $2960-2850$ & $\equiv \mathrm{C}-\mathrm{H}$ & $\sqrt{ }$ & $\sqrt{ }$ & $\sqrt{ }$ & $\sqrt{ }$ \\
\hline Carboxylic acid & $3000-2500$ & $-\mathrm{COOH}$ & $\sqrt{ }$ & $\sqrt{ }$ & $\sqrt{ }$ & $\sqrt{ }$ \\
\hline Zone 3 & 2380-1990 & & & & & \\
\hline Alkyne & $2260-2000$ & $-\mathrm{C} \equiv \mathrm{C}-$ & $x$ & $x$ & $x$ & $x$ \\
\hline Zone 4 & $1850-1650$ & & & & & \\
\hline Ketone & $1750-1705$ & $=\mathrm{C}=\mathrm{O}$ & $\sqrt{ }$ & $\sqrt{ }$ & $\sqrt{ }$ & $\sqrt{ }$ \\
\hline Aldehyde & $1740-1720$ & $>\mathrm{C}=\mathrm{O}$ & $x$ & $x$ & $x$ & $x$ \\
\hline Zone 5 & $1650-1450$ & & & & & \\
\hline Alkene & $1650-1620$ & $=\mathrm{C}=\mathrm{C}=$ & $x$ & $x$ & $x$ & $x$ \\
\hline Benzene & $\sim 1600$ and $\sim 1500$ & Benzene ring & $\times$ & $\times$ & $x$ & $\times$ \\
\hline $\begin{array}{l}\text { C-H bond stretching } \\
\text { vibration in presence } \\
\text { of alkenes }\end{array}$ & $1470-1450$ & $\equiv \mathrm{C}-\mathrm{H}$ & $\sqrt{ }$ & $\sqrt{ }$ & $\sqrt{ }$ & $\sqrt{ }$ \\
\hline
\end{tabular}

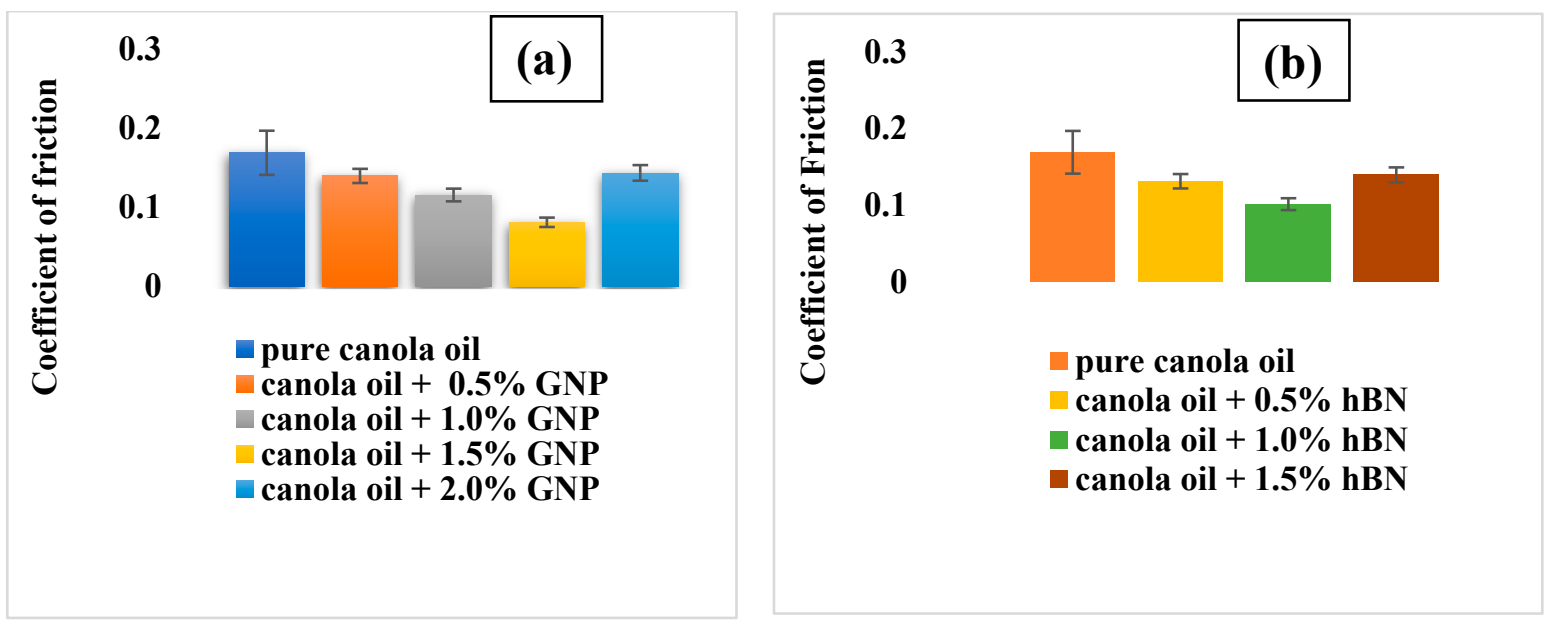

Figure 5. Coefficient of friction at the end of the test for pure canola oil and (a) canola oil with GNP, (b) canola oil with hBN. 


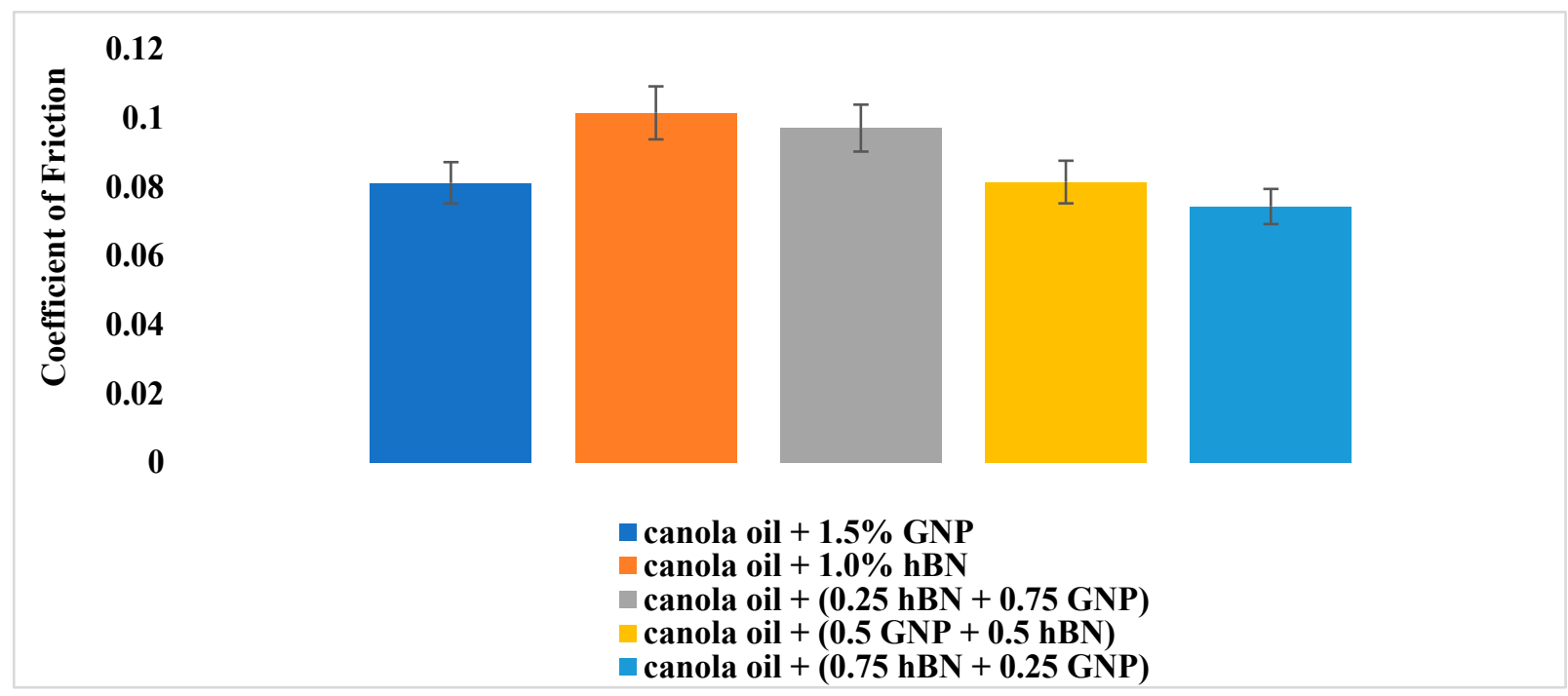

Figure 6. Coefficient of friction data at the end of the test for the canola oil-based nano lubricants.

\subsection{Wear Volume Analysis}

The ball-on-disk experiments performed in this study also exhibited significant improvements in the wear volume study apart from the COF data. The variation in wear volume with an increase in GNP concentration can be seen in Figure 7a. The incorporation of $0.5,1.0,1.5$, and $2.0 \mathrm{wt}$. $\%$ GNP helped in reducing the wear volume by $68,77,85$, and $82 \%$ compared to the pure canola oil. It was observed that $1.5 \mathrm{wt} . \%$ GNP nano lubricant sample provided the lowest wear volume and was considered to be the optimum concentration. However, when the GNP was added beyond the optimum concentration, it led to an increase in wear volume. This observation could be explained by a few reasons [19]. If the concentration of GNP was beyond the optimum composition, it could lower the lubrication of the nano lubricant due to agglomeration at the interface of the tribo-pair $[19,49]$. This will consequently lead to higher wear. The agglomerated GNPs at the interface of the tribo-pair might not lead to the formation of smooth surfaces. This too might result in higher wear. The excess concentration of GNP might also restrict the formation of a uniform lubricant film. This could also lead to higher wear.

Similarly, Figure $7 \mathrm{~b}$ highlights the variation in wear volume with an increase in the $\mathrm{hBN}$ concentration. It was observed that on the incorporation of small amounts of $\mathrm{hBN}$ in the canola oil, the wear volume is decreased. On incorporation of $0.5,1.0$, and $1.5 \mathrm{wt} . \%$ of $\mathrm{hBN}$ into the canola oil, there was a reduction in wear volume by 13,40 , and $10 \%$ compared to pure canola oil. Here it was observed that the $1.0 \mathrm{wt} . \% \mathrm{hBN}$ sample exhibited the lowest wear volume and was considered to be the optimum concentration. The plot in this figure followed a similar type as that of the COF plot shown in Figure 5b.

Figure 8 shows the wear volume pertaining to optimum canola oil-based nano lubricants as well as their hybrid mixture of nano lubricants. It was observed that the hybrid lubricant mixtures [canola oil + $(0.25 \mathrm{hBN}+0.75 \mathrm{GNP})]$, [canola oil + $(0.5 \mathrm{hBN}+0.5 \mathrm{GNP})$ ], and [canola oil $+(0.75 \mathrm{hBN}+0.25 \mathrm{GNP})]$ provided a reduction of wear volume by 90 , 80 , and $73 \%$ compared to the pure canola oil. It was noted that a higher concentration of $\mathrm{hBN}$ in the hybrid nano lubricant mixture was not beneficial for reducing wear volume. It could be observed that the mixture [canola oil $+(0.25 \mathrm{hBN}+0.75 \mathrm{GNP})]$ was providing a synergistic result compared to the other formulated nano lubricants.

There is an anticipation that this hybrid mixture provided a more resilient tribo-film which also reduced its susceptibility of getting removed from the worn disk surface. As a result, the wear volume was the lowest observed from this sample. 

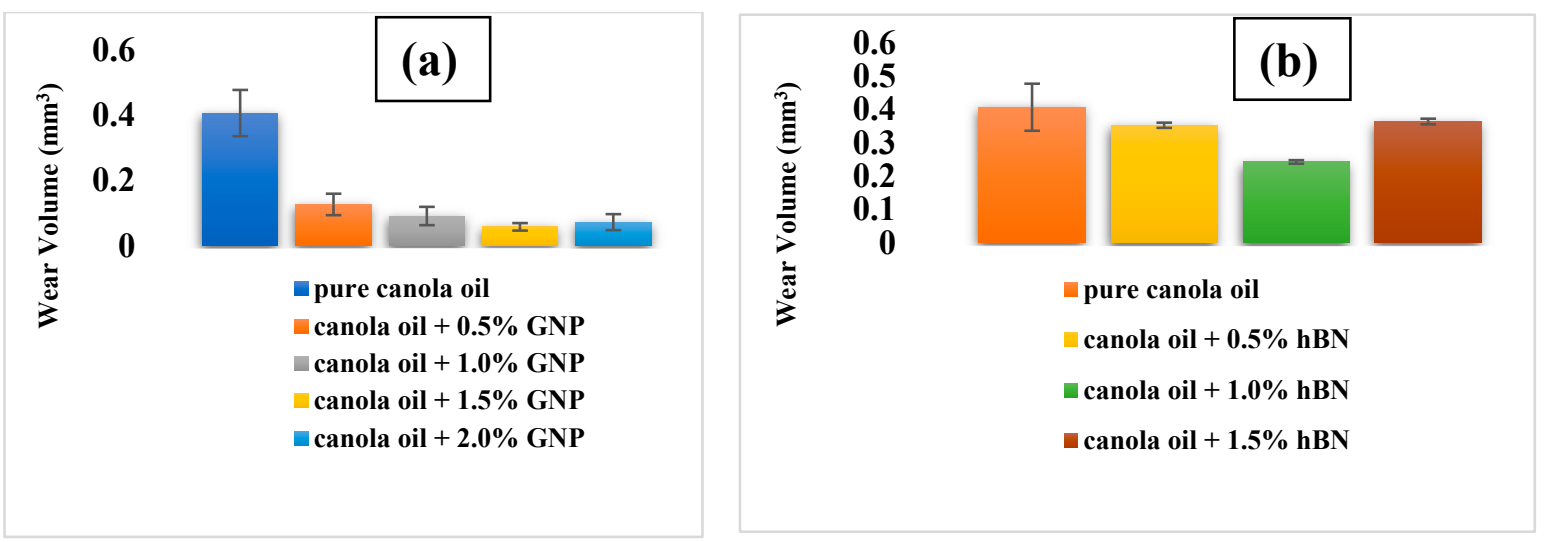

Figure 7. Wear volume data for (a) canola oil with GNP and (b) canola oil with hBN.

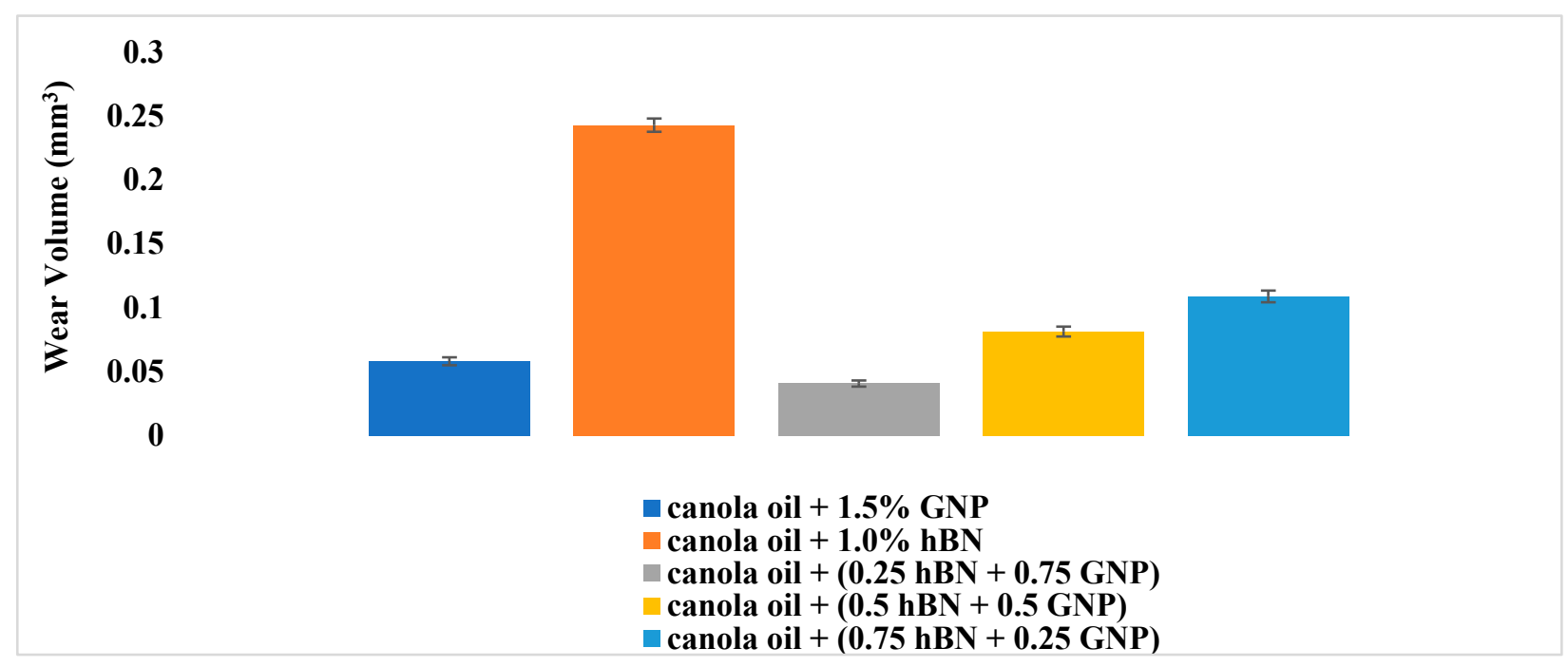

Figure 8. Wear volume data for optimum canola oil-based nano lubricants and hybrid mixture nano lubricants.

\subsection{Worn Surface Analysis}

The 3D worn disk surfaces obtained by an optical profilometer are shown in Figure 9. Corresponding to the 3D image of worn disks, the 2D wear profile of the disk samples is also highlighted. It was observed that the disk sample incorporated with the hBN nano additives exhibited the smoothest wear track. Additionally, the disk sample consisting of the hybrid nano lubricant mixture [canola oil $+(0.25 \mathrm{hBN}+0.75 \mathrm{GNP})]$ exhibited a significant reduction in wear volume compared to the other two worn tracks shown in Figure 9. 
(a)

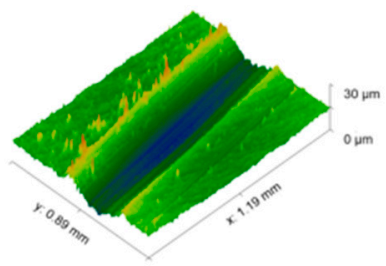

(c)

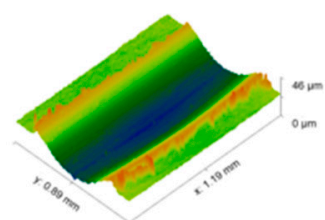

(e)

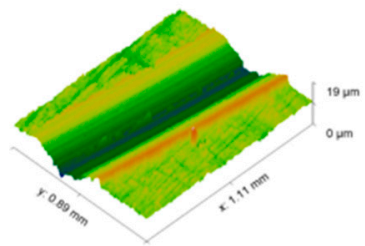

(b)
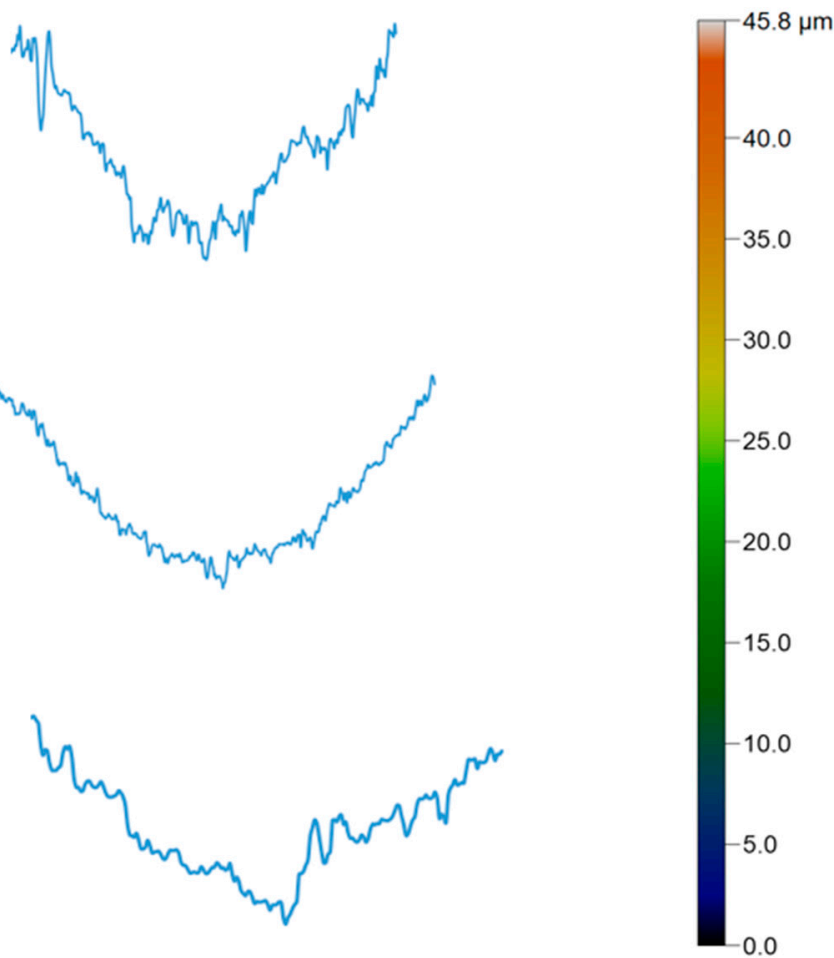

Figure 9. 3D optical profilometer images (10X magnification with scan area of $1.19 \times 0.89 \mathrm{~mm}^{2}$ ) and 2D images of worn disk for $(\mathbf{a}, \mathbf{b})$ canola oil $+1.5 \% \mathrm{GNP},(\mathbf{c}, \mathbf{d})$ canola oil $+1.0 \% \mathrm{hBN}$, and $(\mathbf{e}, \mathbf{f})[$ canola oil $+(0.25 \mathrm{hBN}+0.75 \mathrm{GNP})]$ samples.

\section{Friction and Wear Mechanisms}

The friction and wear mechanisms of this study are explained in Figure 10. When the pure canola oil is employed, the tribo-pair surfaces TP1 and TP2 as shown in Figure 10a almost touch each other. This might result in the formation of scratches. The softer tribopair asperities will deform and produce wear debris which might get entangled during the ball-on-disk test. As a result, there will be an increase in friction. The presence of higher oleic acid in the canola oil has been experimentally shown to help in lowering the COF [41]. On the incorporation of GNP and hBN additives into the canola oil, they can enter the asperities and slide between the tribo-pair surfaces (Figure 10b,c). GNP provides lower shear strength thereby helping in lower friction. During sliding motion, the $\mathrm{hBN}$ orient their layers parallel to the direction of motion and slide over each other, thereby providing lower friction too. In addition, the mentioned nano additives can reduce the roughness of the worn-out surfaces during the friction tests. This is also known as the polishing effect of the nano additives. The nano additives also help in the formation of a tribolayer that can protect the tribo-pair surfaces from forming damage. When the hybrid mixture of hBN and GNP is incorporated into the canola oil, it will result in the formation of a composite tribo-film (Figure 10d). The hybrid mixture of GNP and hBN also results in the formation of heterostructures. Leven et al. [50] had forecasted by a simulation study that there exists a superlubricity state between the sliding interface of boron nitride and graphene layers that lead to a low friction state in their heterostructures. In another simulation study, Mandelli et al. [51] observed that for small contact sizes, the heterostructures of graphene and hBN exhibited superlubricity behavior at heterogeneous junctions during sliding. These factors explain that the conjugate influence of $\mathrm{hBN}$ and GNP resulted in a synergistic lubricating effect on the tribo-pair in our experimental study. The hybrid lubricant mixture having a higher concentration of GNP with multiple stacked layers will help in developing an anticipated stronger layer that will significantly safeguard the tribo-pair from further damage. 
(a)

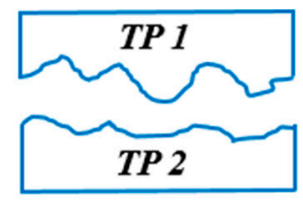

(b)

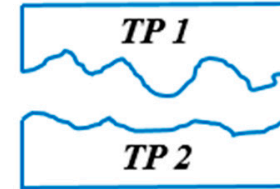

(c)
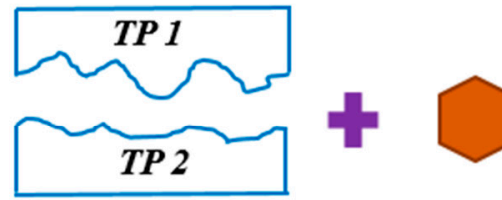

(d)

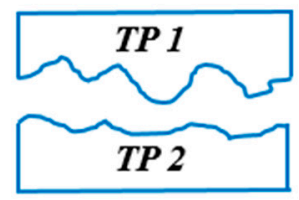

\section{.}
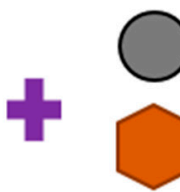
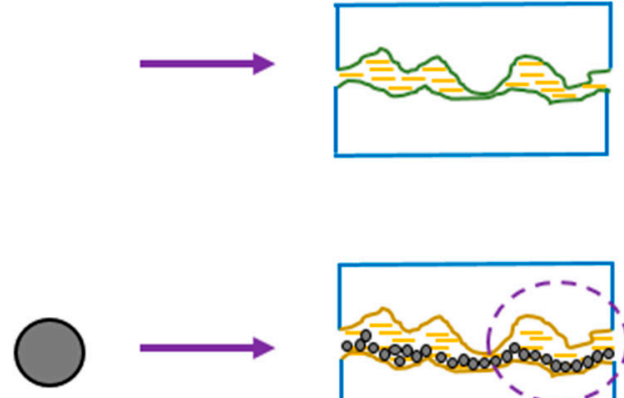

TP 1: Tribo-pair 1

TP 2: Tribo-pair 2

GNP

$\mathrm{hBN}$

Pure CO
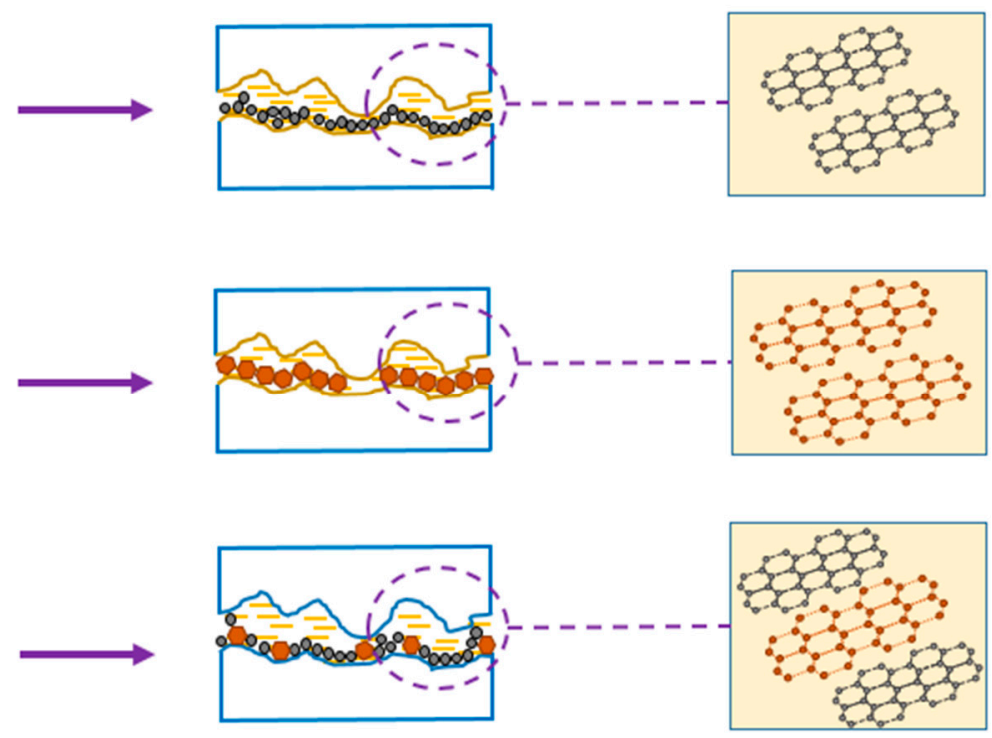

Figure 10. Schematic diagram explaining lubrication mechanism of (a) pure canola oil, (b) canola oil + 1.5 wt.\% GNP, (c) canola oil + 1.0. wt.\% hBN, and (d) [canola oil + (hBN + GNP)] samples. [CO means canola oil].

This synergistic lubricating effect exhibited by the hybrid mixture of nano lubricant can help in significant energy savings and enhance the performance of the tribo-pairs in the future. More research on this subject needs to develop to serve the needs of the lubricant market and promote demands for alternative sustainable, environmentally friendly products.

\section{Summary}

These experiments attempted to highlight a sustainable energy study with a focus on environment-friendly lubricant of canola oil. The study highlights the significant improvement in the tribological behavior of canola oil when incorporated with non-toxic additives like hBN and GNP. Further, the positive synergistic lubrication behavior when $\mathrm{hBN}$ and GNP are mixed to form a hybrid nano lubricant is also explained. Some of the main observations noted from this study are:

1. The dynamic viscosity of pure canola oil increases with the incorporation of nano additives.

2. The FTIR data provides an idea of the various chemical functional groups present in the canola oil.

3. The-ball-on-disk test shows that $1.5 \mathrm{wt} . \%$ GNP nano lubricant exhibited the lowest COF and wear volume. Similarly, the $1.0 \mathrm{wt} . \% \mathrm{hBN}$ nano lubricant exhibits the lowest $\mathrm{COF}$ and wear volume.

4. When hBN and GNP are mixed and incorporated into the canola oil, they exhibit significant improvement in friction and wear behavior.

5. A synergistic effect between $\mathrm{hBN}$ and GNP takes place when incorporated into the canola oil to form a hybrid nano lubricant mixture (especially the mixture containing higher hBN) pertaining to the COF. On the other hand, the hybrid mixture containing higher GNP exhibited the lowest wear volume. 
Author Contributions: S.S.: Methodology, Investigation, Formal analysis, Data curation, Writing original draft. M.H.R.: Methodology, Writing—review and editing, P.L.M.: Supervision, Conceptualization, Visualization. All authors have read and agreed to the published version of the manuscript.

Funding: The authors received no financial support for the research, authorship, and/or publication of this article.

Institutional Review Board Statement: Not applicable.

Informed Consent Statement: Not applicable.

Data Availability Statement: Not applicable.

Acknowledgments: The authors would like to thank the Department of Mechanical Engineering, University of Nevada Reno for providing the equipment and testing facilities.

Conflicts of Interest: The authors declare no potential conflicts of interest with respect to the research, authorship, and/or publication of this article.

\section{References}

1. Lovell, M.R.; Kabir, M.; Menezes, P.L.; Higgs, C.F., III. Influence of boric acid additive size on green lubricant performance. Philos. Trans. R. Soc. A Math. Phys. Eng. Sci. 2010, 368, 4851-4868. [CrossRef] [PubMed]

2. Fox, N.J.; Tyrer, B.; Stachowiak, G.W. Boundary Lubrication Performance of Free Fatty Acids in Sunflower Oil. Tribol. Lett. 2004, 16, 275-281. [CrossRef]

3. Erhan, S.Z.; Sharma, B.K.; Liu, Z.; Adhvaryu, A. Lubricant base stock potential of chemically modified vegetable oils. J. Agric. Food Chem. 2008, 56, 8919-8925. [CrossRef]

4. Lundgren, S.M.; Persson, K.; Mueller, G.; Kronberg, B.; Clarke, J.; Chtaib, M.; Claesson, P.M. Unsaturated fatty acids in alkane solution: Adsorption to steel surfaces. Langmuir 2007, 23, 10598-10602. [CrossRef]

5. Reeves, C.J.; Menezes, P.L. Advancements in eco-friendly lubricants for tribological applications: Past, present, and future. In Ecotribology; Springer: Berlin/Heidelberg, Germany, 2016; pp. 41-61.

6. Li, W.; Kong, X.H.; Ruan, M.; Ma, F.M.; Jiang, Y.F.; Liu, M.Z.; Chen, Y.; Zuo, X.H. Green waxes, adhesives and lubricants. Philos. Trans. R. Soc. A Math. Phys. Eng. Sci. 2010, 368, 4869-4890. [CrossRef] [PubMed]

7. Jayadas, N.; Nair, K.P. Coconut oil as base oil for industrial lubricants-Evaluation and modification of thermal, oxidative and low temperature properties. Tribol. Int. 2006, 39, 873-878. [CrossRef]

8. Liu, Y.; Binks, B.P. Foams of vegetable oils containing long-chain triglycerides. J. Colloid Interface Sci. 2021, 583, 522-534. [CrossRef]

9. Salih, N.; Salimon, J.; Yousif, E. The physicochemical and tribological properties of oleic acid based triester biolubricants. Ind. Crop. Prod. 2011, 34, 1089-1096. [CrossRef]

10. Omrani, E.; Menezes, P.L.; Rohatgi, P.K. Effect of micro-and nano-sized carbonous solid lubricants as oil additives in nanofluid on tribological properties. Lubricants 2019, 7, 25. [CrossRef]

11. Reeves, C.J.; Menezes, P.L.; Lovell, M.R.; Jen, T.-C. The size effect of boron nitride particles on the tribological performance of biolubricants for energy conservation and sustainability. Tribol. Lett. 2013, 51, 437-452. [CrossRef]

12. Singh, Y.; Farooq, A.; Raza, A.; Mahmood, M.A.; Jain, S. Sustainability of a non-edible vegetable oil based bio-lubricant for automotive applications: A review. Process. Saf. Environ. Prot. 2017, 111, 701-713. [CrossRef]

13. Panchal, T.M.; Patel, A.; Chauhan, D.; Thomas, M.; Patel, J.V. A methodological review on bio-lubricants from vegetable oil based resources. Renew. Sustain. Energy Rev. 2017, 70, 65-70. [CrossRef]

14. Chowdary, K.; Kotia, A.; Lakshmanan, V.; Elsheikh, A.H.; Ali, M.K.A. A review of the tribological and thermo-physical mechanisms of bio-lubricants based nanomaterials in automotive applications. J. Mol. Liq. 2021, 339, 116717. [CrossRef]

15. Bartz, W.J. Ecotribology: Environmentally acceptable tribological practices. Tribol. Int. 2006, 39, 728-733. [CrossRef]

16. Reeves, C.J.; Menezes, P.L. Evaluation of boron nitride particles on the tribological performance of avocado and canola oil for energy conservation and sustainability. Int. J. Adv. Manuf. Technol. 2016, 89, 3475-3486. [CrossRef]

17. Gulzar, M.; Masjuki, H.H.; Kalam, M.A.; Varman, M.; Zulkifli, N.W.M.; Mufti, R.A.; Zahid, R. Tribological performance of na-noparticles as lubricating oil additives. J. Nanoparticle Res. 2016, 18, 1-25. [CrossRef]

18. Reeves, C.J.; Siddaiah, A.; Menezes, P.L. A review on the science and technology of natural and synthetic bio-lubricants. J. Bio-Tribo-Corros. 2017, 3, 11. [CrossRef]

19. Omrani, E.; Siddaiah, A.; Moghadam, A.D.; Garg, U.; Rohatgi, P.; Menezes, P.L. Ball Milled Graphene Nano Additives for Enhancing Sliding Contact in Vegetable Oil. Nanomaterials 2021, 11, 610. [CrossRef] [PubMed]

20. Reeves, C.J.; Menezes, P.L.; Lovell, M.R.; Jen, T.-C. The influence of surface roughness and particulate size on the tribological performance of bio-based multi-functional hybrid lubricants. Tribol. Int. 2015, 88, 40-55. [CrossRef]

21. John, M.; Menezes, P.L. Self-Lubricating Materials for Extreme Condition Applications. Materials 2021, 14, 5588. [CrossRef]

22. Lisuzzo, L.; Hueckel, T.; Cavallaro, G.; Sacanna, S.; Lazzara, G. Pickering emulsions based on wax and halloysite nanotubes: An ecofriendly protocol for the treatment of archeological woods. ACS Appl. Mater. Interfaces 2020, 13, 1651-1661. [CrossRef] [PubMed] 
23. Cavallaro, G.; Milioto, S.; Nigamatzyanova, L.; Akhatova, F.; Fakhrullin, R.F.; Lazzara, G. Pickering Emulsion Gels Based on Halloysite Nanotubes and Ionic Biopolymers: Properties and Cleaning Action on Marble Surface. ACS Appl. Nano Mater. 2019, 2, 3169-3176. [CrossRef]

24. Yu, L.; Li, S.; Stubbs, L.P.; Lau, H.C. Characterization of clay-stabilized, oil-in-water Pickering emulsion for potential conformance control in high-salinity, high-temperature reservoirs. Appl. Clay Sci. 2021, 213, 106246. [CrossRef]

25. Suresha, B.; Hemanth, G.; Rakesh, A.; Adarsh, K. Tribological behaviour of neem oil with and without graphene nanoplatelets using four-ball tester. Adv. Tribol. 2020, 2020, 1984931. [CrossRef]

26. Dai, W.; Kheireddin, B.; Gao, H.; Liang, H. Roles of nanoparticles in oil lubrication. Tribol. Int. 2016, 102, 88-98. [CrossRef]

27. Talib, N.; Sasahara, H.; Rahim, E.A. Evaluation of modified jatropha-based oil with hexagonal boron nitride particle as a biolubricant in orthogonal cutting process. Int. J. Adv. Manuf. Technol. 2017, 92, 371-391. [CrossRef]

28. Suresha, B.; Hemanth, G.; Padmanabha, A.; Prasanna, S.I.; Kulkarni, G.; Charan, M.R.S.; Amith, R. Tribological characteristics of mahua oil with graphene nanoplatelets as anti-wear and extreme pressure additive. Surf. Topogr. Metrol. Prop. 2021, 9, 045008. [CrossRef]

29. Bhaumik, S.; Paleu, V.; Pathak, R.; Maggirwar, R.; Katiyar, J.K.; Sharma, A.K. Tribological investigation of r-GO additived biodegradable cashew nut shells liquid as an alternative industry lubricant. Tribol. Int. 2019, 135, 500-509. [CrossRef]

30. Bhaumik, S.; Datta, S.; Pathak, S.D. Analyses of tribological properties of castor oil with various carbonaceous micro- and nano-friction modifiers. J. Tribol. 2017, 139, 061802. [CrossRef]

31. Bahari, A.; Lewis, R.; Slatter, T. Friction and wear phenomena of vegetable oil-based lubricants with additives at severe sliding wear conditions. Tribol. Trans. 2018, 61, 207-219. [CrossRef]

32. Kasar, A.K.; Menezes, P.L. Synthesis and recent advances in tribological applications of graphene. Int. J. Adv. Manuf. Technol. 2018, 97, 3999-4019. [CrossRef]

33. Berman, D.; Erdemir, A.; Sumant, A.V. Graphene: A new emerging lubricant. Mater. Today 2014, 17, 31-42. [CrossRef]

34. Talib, N.; Nasir, R.; Rahim, E. Tribological behaviour of modified jatropha oil by mixing hexagonal boron nitride nanoparticles as a bio-based lubricant for machining processes. J. Clean. Prod. 2017, 147, 360-378. [CrossRef]

35. Gupta, M.K.; Bijwe, J.; Kadiyala, A.K. Tribo-investigations on oils with dispersants and hexagonal boron nitride particles. J. Tribol. 2018, 40, 441-456. [CrossRef]

36. Düzcükoğlu, H.; Sahin, Ö.S. Investigation of wear performance of canola oil containing boric acid under boundary friction condition. Tribol. Trans. 2010, 54, 57-61. [CrossRef]

37. Caballero, B. (Ed.) Encyclopedia of Food Sciences and Nutrition, 2nd ed.; Academic Press: Cambridge, MA, USA, 2003.

38. Dhanola, A.; Garg, H. Dispersion stability and rheology study of canola oil containing $\mathrm{TiO}_{2}$ nanoadditives for tribological applications: An experimental approach. Proc. Inst. Mech. Eng. Part J J. Eng. Tribol. 2020, 235, 1350650120973793. [CrossRef]

39. Wu, Y.; Li, W.; Wang, X. The influence of oxidation on the tribological performance of diester lubricant. Lubr. Sci. 2014, 26, 55-65. [CrossRef]

40. Rahman, H.; Bhoi, P.R.; Saha, A.; Patil, V.; Adhikari, S. Thermo-catalytic co-pyrolysis of biomass and high-density polyethylene for improving the yield and quality of pyrolysis liquid. Energy 2021, 225, 120231. [CrossRef]

41. Reeves, C.J.; Menezes, P.L.; Jen, T.C.; Lovell, M.R. The influence of fatty acids on tribological and thermal properties of natural oils as sustainable biolubricants. Tribol. Int. 2015, 90, 123-134. [CrossRef]

42. Ahammed, N.; Asirvatham, L.G.; Wongwises, S. Effect of volume concentration and temperature on viscosity and surface tension of graphene-water nanofluid for heat transfer applications. J. Therm. Anal. Calorim. 2016, 123, 1399-1409. [CrossRef]

43. Chakraborty, S.; Panigrahi, P.K. Stability of nanofluid: A review. Appl. Therm. Eng. 2020, 174, 115259. [CrossRef]

44. Ali, I.; Basheer, A.A.; Kucherova, A.; Memetov, N.; Pasko, T.; Ovchinnikov, K.; Pershin, V.; Kuznetsov, D.; Galunin, E.; Grachev, V.; et al. Advances in carbon nanomaterials as lubricants modifiers. J. Mol. Liq. 2019, 279, 251-266. [CrossRef]

45. Talib, N.; Rahim, E. Performance of modified jatropha oil in combination with hexagonal boron nitride particles as a bio-based lubricant for green machining. Tribol. Int. 2018, 118, 89-104. [CrossRef]

46. Qi, S.; Geng, Z.; Lu, Z.; Zhang, G.; Wu, Z. Synergistic Lubricating Behaviors of 3D Graphene and 2D Hexagonal Boron Nitride Dispersed in PAO4 for Steel/Steel Contact. Adv. Mater. Interfaces 2020, 7, 1901893. [CrossRef]

47. Azman, N.F.; Samion, S. Dispersion Stability and Lubrication Mechanism of Nanolubricants: A Review. Int. J. Precis. Eng. Manuf. Technol. 2019, 6, 393-414. [CrossRef]

48. Anand, R.; Raina, A.; Haq, M.I.U.; Mir, M.J.; Gulzar, O.; Wani, M.F. Synergism of $\mathrm{TiO}_{2}$ and Graphene as Nano-Additives in Bio-Based Cutting Fluid-An Experimental Investigation. Tribol. Trans. 2021, 64, 350-366. [CrossRef]

49. Ahmed Abdalglil Mustafa, W.; Dassenoy, F.; Sarno, M.; Senatore, A. A review on potentials and challenges of nanolubricants as promising lubricants for electric vehicles. Lubr. Sci. 2021, 34, 1-29. [CrossRef]

50. Leven, I.; Krepel, D.; Shemesh, O.; Hod, O. Robust Superlubricity in Graphene/h-BN Heterojunctions. J. Phys. Chem. Lett. 2013, 4, 115-120. [CrossRef]

51. Mandelli, D.; Leven, I.; Hod, O.; Urbakh, M. Sliding friction of graphene/hexagonal-boron nitride heterojunctions: A route to robust superlubricity. Sci. Rep. 2017, 7, 10851. [CrossRef] 